\title{
Reproductive conflicts and egg discrimination in a socially polymorphic ant
}

\author{
Joël Meunier • Luma Delaplace • Michel Chapuisat
}

Received: 24 February 2010 /Revised: 27 April 2010 /Accepted: 29 April 2010 /Published online: 14 May 2010

(C) Springer-Verlag 2010

\begin{abstract}
The ability to discriminate against competitors shapes cooperation and conflicts in all forms of social life. In insect societies, workers may detect and destroy eggs laid by other workers or by foreign queens, which can contribute to regulate reproductive conflicts among workers and queens. Variation in colony kin structure affects the magnitude of these conflicts and the diversity of cues used for discrimination, but the impact of the number of queens per colony on the ability of workers to discriminate between eggs of diverse origin has so far not been investigated. Here, we examined whether workers from the socially polymorphic ant Formica selysi distinguished eggs laid by nestmate workers from eggs laid by nestmate queens, as well as eggs laid by foreign queens from eggs laid by nestmate queens. Workers from single- and multiple-queen colonies discriminated worker-laid from queen-laid eggs, and eliminated the former. This suggests that workers collectively police each other in order to limit the colony-level costs of worker reproduction and not because of
\end{abstract}

Communicated by L. Sundström

J. Meunier $(\bowtie) \cdot$ L. Delaplace $\cdot$ M. Chapuisat

Department of Ecology and Evolution, Biophore, Unil-Sorge,

University of Lausanne,

1015 Lausanne, Switzerland

e-mail: joel.meunier@unibas.ch

L. Delaplace

e-mail: luma.delaplace@gmail.com

M. Chapuisat

e-mail: Michel.Chapuisat@unil.ch

Present Address:

J. Meunier

Zoological Institute, Evolutionary Biology, University of Basel,

Vesalgasse 1,

4056 Basel, Switzerland relatedness differences towards queens' and workers' sons. Workers from single-queen colonies discriminated eggs laid by foreign queens of the same social structure from eggs laid by nestmate queens. In contrast, workers from multiple-queen colonies did not make this distinction, possibly because cues on workers or eggs are more diverse. Overall, these data indicate that the ability of $F$. selysi workers to discriminate eggs is sufficient to restrain worker reproduction but does not permit discrimination between matrilines in multiple-queen colonies.

Keywords Worker policing - Nestmate recognition . Social insect · Ants · Hymenoptera Formica selysi

\section{Introduction}

The evolution of integrated societies requires processes moderating within-group conflicts and preventing groupexploitation by foreigners (Szathmary and Maynard Smith 1995; Keller and Chapuisat 1999; Michod and Roze 2001; Ratnieks et al. 2006). In insect societies, egg discrimination by workers may play an important role in both contexts. First, workers may distinguish and eliminate eggs laid by nestmate workers, and by so doing enforce their collective interest (leaving male production to the queens) over their individual interests (producing sons (Ratnieks 1988; Frank 1995; Wenseleers and Ratnieks 2006)). Second, workers may discriminate against eggs laid by foreign queens to prevent the exploitation and progressive invasion of colonies by unrelated conspecifics (Hamilton 1964; Crozier and Pamilo 1996).

Workers from many Hymenopteran societies (ants, bees, and wasps) are known to police the reproduction of nestmate workers. They either eliminate worker-laid eggs 
that would otherwise develop into males or behave aggressively towards workers with developed ovaries (Ratnieks 1988; reviewed in Wenseleers and Ratnieks 2006; Helanterä and Sundström 2007b; van Zweden et al. 2007). Two major factors may promote worker policing. First, workers should police each other when they are on average more related to queen-produced males than to worker-produced males (the relatedness asymmetry hypothesis). Second, workers should prevent worker reproduction if it decreases colony productivity (the colony-level efficiency hypothesis). Both hypotheses are based on kin selection: policing evolves when workers increase their inclusive fitness by preventing the reproduction of other workers. However, the respective importance of each hypothesis remains a matter of debate (Hammond and Keller 2004; Wenseleers and Ratnieks 2006).

According to the relatedness asymmetry hypothesis, worker policing should depend on the social structure of the colony. Workers should police each other in colonies headed by one queen that had mated with more than two males, or in colonies headed by many queens of moderate to high relatedness (Ratnieks 1988; Crozier and Pamilo 1996). A comparative analysis provided partial support to the relatedness asymmetry hypothesis: the 75 species of social Hymenoptera wherein workers were most closely related to worker-produced males had a greater proportion of males produced by workers $(14 \%)$ than the 15 species wherein workers were most closely related to queen-produced males (which had less than $2 \%$ of worker-produced males); (e.g., Foster et al. 2002; Iwanishi et al. 2003; reviewed Wenseleers and Ratnieks 2006). However, policing is also common in species with one singly mated queen, in which workers are more related to the sons of other workers than to the sons of the queens (e.g., Foster et al. 2002; Iwanishi et al. 2003; reviewed Wenseleers and Ratnieks 2006). This suggests that relatedness asymmetry is not the only factor selecting for worker policing.

According to the efficiency hypothesis, worker policing evolves because the colony-level costs of worker reproduction exceed the inclusive fitness gains of rearing workers' sons instead of queens' sons (Ratnieks 1988; Hammond and Keller 2004; Wenseleers and Ratnieks 2006). Worker reproduction can decrease colony efficiency, and hence colony productivity, if reproducing workers work less (Cole 1986; Gobin et al. 2003), or if competition among reproducing workers leads to an over-production of eggs that exceeds the rearing capacity of the colony (Hardin 1968; Wenseleers et al. 2004). Despite these potential costs, workers rear a large proportion of workers' sons in some species (reviewed in Hammond and Keller 2004; Wenseleers and Ratnieks 2006), which suggests that the costs and benefits of worker reproduction vary among species and depend on colony life history (e.g., Dijkstra and Boomsma 2007).
The ability of workers to discriminate nestmate from foreign eggs is important to maintain colony integrity. In various social insect species, conspecific queens occasionally infiltrate established colonies (Beekman and Oldroyd 2008; Holzer et al. 2008a). This dilutes the relatedness among nestmates and decreases the inclusive fitness of resident workers (Hamilton 1964; Crozier and Pamilo 1996). Inter-specific social parasitism is also frequent in ants, with parasitic queens taking over the nests of their host species to lay their own brood (e.g., Kutter 1977). Hence, resident workers should endeavor to eliminate non-nestmate queens and their brood, whereas the foreign queens and brood should try to escape detection.

Workers from numerous ant species aggressively reject foreign queens seeking adoption in their colonies (e.g., Sundström 1997; Kikuchi et al. 2007; but see Vasquez and Silverman 2008; Holzer et al. 2008b). In contrast, workers frequently do not discriminate against foreign queen-laid eggs (e.g., Ratnieks and Visscher 1989; Foster and Ratnieks 2001; Martin et al. 2002; Pirk et al. 2003; Endler et al. 2004). Proximately, it has been suggested that this absence of discrimination was due to an "acceptance" pheromone signal displayed on queen-laid eggs and conserved across colonies (Vander Meer et al. 1998). Ultimately, egg discrimination may be selected against because discrimination errors or nepotistic behavior generated by competition among matrilines within colonies are costly (Keller 1997; Holzer et al. 2006). Recent studies did however find evidence that workers were able to discriminate against eggs laid by foreign queens in the ant Formica fusca (Helanterä and Sundström 2007a) and the honeybee Apis mellifera (Pirk et al. 2007). These new results call for further studies on the ability of workers to discriminate against foreign eggs, as well as on the factors modulating workers' response towards nestmate and foreign queen-laid eggs.

Variation in colony kin structure might affect nestmate discrimination by modifying the degree of relatedness within colonies and the diversity of cues used by workers to recognize nestmate from foreigners. To recognize intruders, social insects compare their chemical profile to a learned chemical template that characterizes each colony (Vander Meer and Morel 1998). Colonies with multiple queens contain a broader mix of chemical cues, thus increasing discrimination errors (Hölldobler and Wilson 1977; Breed and Bennett 1987; Vander Meer and Morel 1998) and possibly leading to a higher degree of tolerance towards conspecific foreigners (reviewed in Bourke and Franks 1995; Sundström 1997; but see Rosset et al. 2006). So far, the influence of the number of queens per colony on the ability of workers to discriminate against foreign eggs has not been investigated. 
The aim of this study was to investigate the influence of social structure variation on the ability of workers to discriminate against eggs from various origins. Our model system was the socially polymorphic ant Formica selysi, in which single-queen (monogyne) and multiple-queen (polygyne) colonies coexist in the same population (Chapuisat et al. 2004). There was no sign of genetic differentiation between social forms at microsatellite markers (Chapuisat et al. 2004). Gene flow between social forms may occur because queens originating from both monogyne and polygyne colonies can successfully mate with males from the alternative social form and seem able to found colonies independently (Reber et al. 2010). In our study population, we detected little change in the social structure of colonies when genotyping the same colonies over several years (Chapuisat et al. 2004; Schwander et al. 2005; Rosset et al. 2006; Reber et al. 2008; Meunier and Chapuisat 2009). This suggests that shifts in social structure are rare and that the social conditions may be stable enough to permit the evolution of adaptive brood discrimination by workers depending on the social structure of the colony, provided that the selection pressure is high enough (see also Rosset and Chapuisat 2007; Meunier and Chapuisat 2009 for further differences between social forms).

We used egg-acceptance bioassays to examine whether workers from each type of social background discriminated (1) eggs laid by nestmate workers from eggs laid by nestmate queens, as expected if worker policing occurs and (2) eggs laid by foreign queens from eggs laid by nestmate queens, as expected if nestmate discrimination of eggs occurs. In colonies of our study population, the actual degree of relatedness asymmetry should not promote worker policing (see "Material and methods" section for estimates of relatedness asymmetry). Workers from monogyne colonies are more related to workers' sons than to queens' sons, whereas workers from polygyne colonies are equally related to both types of males. Hence, the relatedness asymmetry hypothesis predicts that workers should not discriminate against eggs laid by nestmate workers, particularly in monogyne colonies. In contrast, the selective elimination of worker-laid eggs in monogyne colonies, or in both types of colonies, would support the efficiency hypothesis (Hammond and Keller 2004; Wenseleers and Ratnieks 2006).

We also predict that workers from polygyne colonies might be more tolerant of eggs laid by foreign queens than workers from monogyne colonies. This prediction could result from either of the two factors: polygyne colonies could contain more diverse recognition cues preventing accurate nestmate discrimination. Alternatively, the cost of intra-colony kin discrimination (nepotism) could select for indiscriminate acceptance of eggs (Keller 1997; Holzer et al. 2006).

\section{Material and methods}

Study species and egg source

Our study population of the ant $F$. selysi is located along the river Rhône in central Valais, Switzerland $\left(7^{\circ} 36^{\prime} 30^{\prime \prime} \mathrm{E}, 46^{\circ}\right.$ $18^{\prime} 30^{\prime \prime} \mathrm{N}$, altitude $565 \mathrm{~m}$ ). The social structure (monogyne or polygyne) of each colony used in this experiment had been previously determined by genotyping eight to 100 workers at nine microsatellite markers (Chapuisat et al. 2004; Schwander et al. 2005; Rosset and Chapuisat 2006; Reber et al. 2008).

Queens in monogyne colonies from our study population are generally singly mated (Chapuisat et al. 2004). Hence, workers from monogyne colonies are on average more related to the sons of other workers than to the sons of the queens. In polygyne colonies, the relatedness towards males depends on the number of queens and relatedness among queens. In general, workers are also more related to the sons of other workers than to the sons of the queens if colonies contain relatively few queens of low relatedness, or when colonies recruit new queens from their own daughters (Pamilo 1991; Crozier and Pamilo 1996). Our microsatellite data from nine polygyne colonies indicate that workers have a similar degree of relatedness to the queens' sons and to the expected sons of workers $(0.067 \pm$ 0.04 and $0.065 \pm 0.01$, respectively, mean $\pm \mathrm{SE}$ ); (Chapuisat et al. 2004; Rosset and Chapuisat 2006). Overall, if worker policing is only caused by relatedness asymmetry, it should be rare or absent in our study population, particularly in monogyne colonies.

Queen-laid eggs were sampled from 23 single-queen and 17 polygyne field colonies during the first week of May 2008. These eggs were the first ones produced in the season, and they develop into queens or males, whereas workers are produced later in the season (Rosset and Chapuisat 2006). We assume that eggs collected in field colonies are queen-produced, because we had previously shown that worker reproduction was absent or very rare in queenright field colonies of our study population. Indeed, we did not detect any worker-produced eggs when genotyping 341 male eggs originating from 27 monogyne queenright field colonies (Rosset and Chapuisat 2006).

Worker-laid eggs were obtained from groups of workers that were experimentally separated from their queens. We sampled 200 workers from each of 25 monogyne and 20 polygyne field colonies during the second week of April 2008 and transferred them to the laboratory. Thirty groups of queenless workers (originating from 16 and 14 monogyne and polygyne colonies, respectively) produced more than 20 eggs, and could thus be included in the egg-acceptance bioassay. We standardized the age of the eggs used in the egg-acceptance bioassays by performing all assays approx- 
imately 10 days after queens and workers had started to lay (that is, between April 30th and May 7th 2008).

Egg-acceptance bioassays

We estimated the collection rate and survival rate of eggs introduced into recipient groups of workers. The recipient workers were sampled between April 30th and May 7th 2008 from 29 and 25 monogyne and polygyne field colonies, respectively. They were distributed in 102 recipient groups, of which 57 and 45 originated from monogyne and polygyne field colonies, respectively (see Figs. 1 and 2 for sample sizes - there were up to three recipient groups per colony, each receiving a set of eggs of different origin). Each recipient group was composed of 100 workers placed in a small plastic box $(15 \times 15 \times 5 \mathrm{~cm})$ lined with fluon. Each box contained one test tube with wet cotton wool that workers used as nest. Workers had ad libitum access to standard ant food (for food composition see Meunier and Chapuisat 2009). To limit the influence of orphaning on workers responses, egg-acceptance bioassays were performed $16 \mathrm{~h}$ after the sampling of workers in the field.

Each recipient group of workers received a set of $29 \pm 7$ (mean $\pm \mathrm{SD}$ ) eggs laid either by (1) nestmate workers, (2) nestmate queens, or (3) queens originating from a foreign colony of the same social structure as the recipient workers. Prior to introduction, we placed eggs in small plastic trays $(3 \times 3 \mathrm{~cm})$ and observed them under a stereomicroscope to check that they were not damaged. We then transferred the trays with eggs into recipient groups.

We estimated egg collection rate in a subsample of 66 recipient groups by counting the number of eggs remaining on the trays $15 \mathrm{~min}$ after their introduction in recipient groups (see Fig. 1 for sample sizes). We estimated egg survival rate by counting the total number of undamaged eggs present in each recipient group of workers $24 \mathrm{~h}$ after introduction (see Fig. 2 for sample sizes).

\section{Experimental controls}

We controlled for two factors that could influence the elimination of worker-laid eggs, namely their laboratory origin and sex. To examine if eggs laid in laboratory colonies were treated differently from eggs laid in field colonies, we compared the response of workers towards foreign queen-laid eggs produced in the laboratory and in the field. To this end, we collected workers from nine polygyne field colonies in the first week of April 2008. Each of these nine additional groups of recipient workers received 30 eggs laid by foreign queens in the laboratory. These queens originated from nine polygyne field colonies and had been kept in the laboratory since March 2007. We then estimated egg collection rate and egg survival rate as described above.

We also examined if differences in the sex of eggs could influence the discrimination of worker-laid and queen-laid eggs. Worker-laid eggs are exclusively haploid (male destined), whereas queen-laid eggs can be a mix of haploid and diploid (male and female destined) eggs. We controlled for this potential effect of sex by restricting one comparison to haploid eggs only. In our study population, the proportion of male pupae produced by field colonies depends on the proportion of haploid eggs laid by the queens (Rosset and Chapuisat 2006). In particular, some of the field colonies specialize in the production of males and
Fig. 1 Collection rates of eggs originating from nestmate workers (black squares), nestmate queens (control, white circles) or foreign queens (black circles) 15 min after being introduced in group of monogyne or polygyne workers. The number of recipient groups of workers is indicated below the SE bars. $* P<0.05$, $* * * P<0.001$

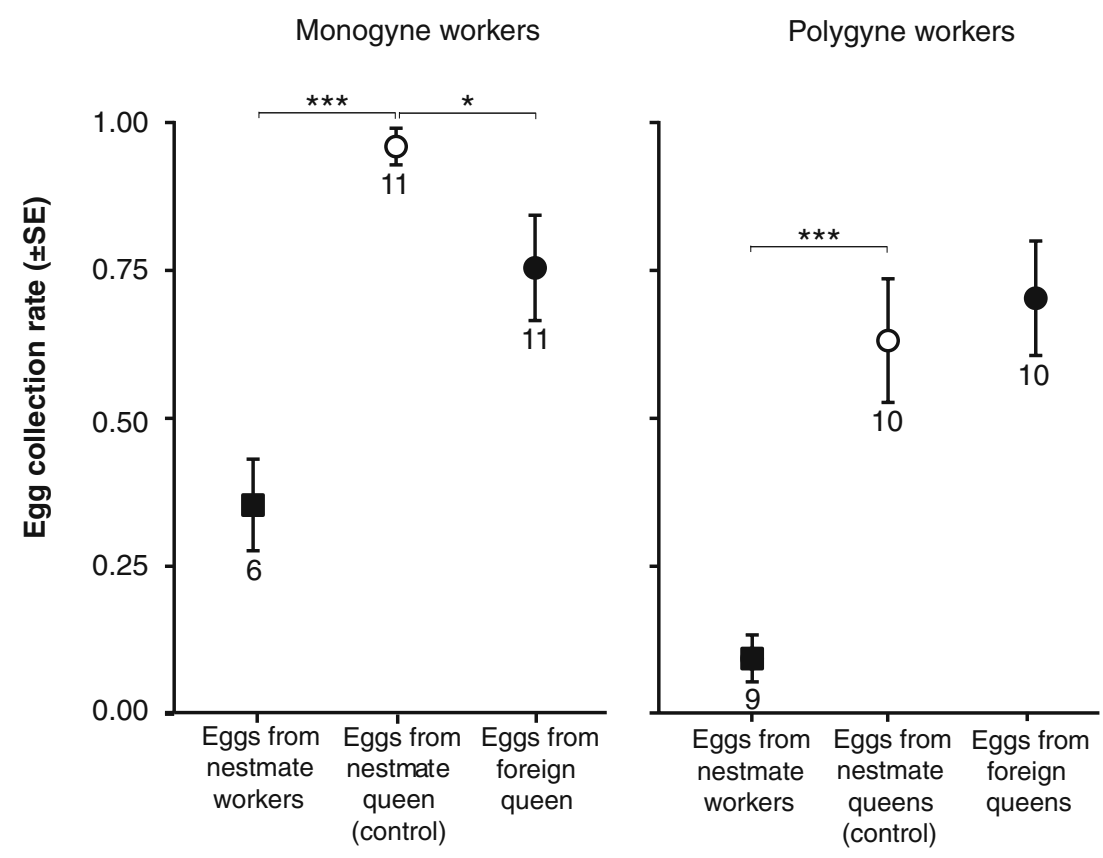


Fig. 2 Survival rates of eggs originating from nestmate workers (black squares), nestmate queens (control, white circles), or foreign queens (black circles) $24 \mathrm{~h}$ after being introduced in group of monogyne or polygyne workers. The number of recipient groups of workers is indicated below the SE bars. $* P<0.05, * * * P<0.001$
Monogyne workers

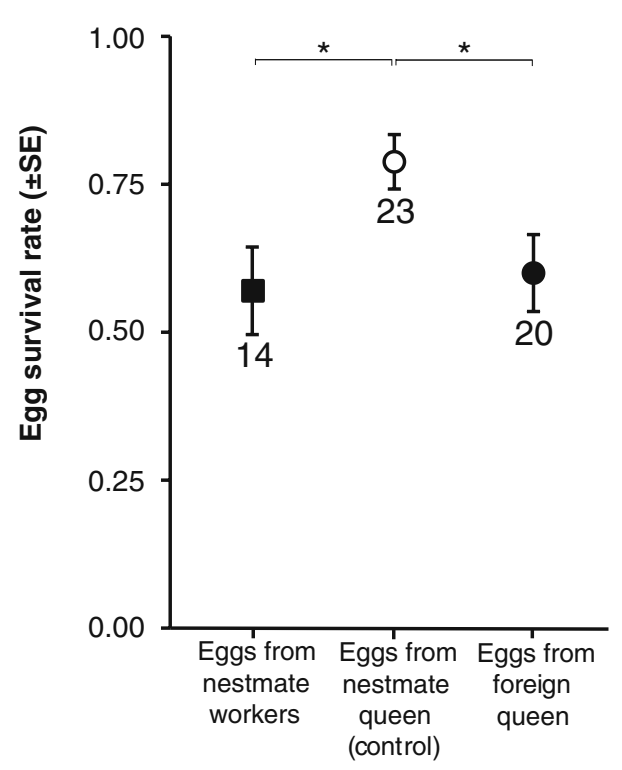

Polygyne workers

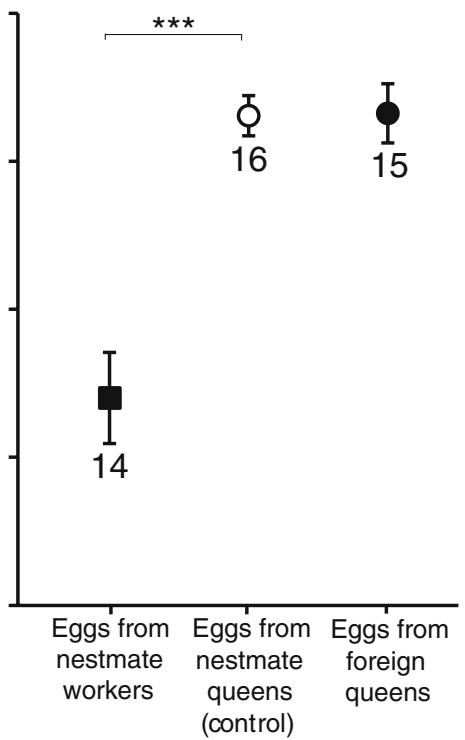

contain only haploid, male-destined queen-laid eggs at this time of the year (Rosset and Chapuisat 2006). We determined the sex of $30 \pm 11$ (mean $\pm \mathrm{SD}$ ) pupae in 22 of the field colonies that were used as source of queen-laid eggs, and identified nine male-specialized colonies, six monogyne, and three polygyne ones, respectively. To examine if workers discriminated worker-laid eggs from queen-laid eggs independently of the sex of eggs, we compared the survival of haploid worker-laid eggs to the ones of haploid queen-laid eggs originating from this subsample of male-specialized field colonies.

\section{Statistical analysis}

We tested if workers discriminated between worker-laid and queen-laid eggs in a two-way analysis of variance (ANOVA). The maternal origin of eggs (workers or queens) and the social structure of workers (monogyne or polygyne) were used as fixed factors. The response variables were the proportion of eggs collected from the trays $15 \mathrm{~min}$ after introduction (egg collection rate) and the proportion of eggs still alive after $24 \mathrm{~h}$ (egg survival rate). Because eggs or workers originating from the same field colony were sometimes used twice in the analyses (albeit once per type of eggs assayed), we included the colony of origin of eggs and workers as random factors in all the ANOVAs. To test whether workers discriminated between foreign and nestmate queen-laid eggs, we used a similar two-way ANOVA in which the origin of eggs (i.e., nestmate or foreign) and the social structure of workers were used as fixed factors.

In addition, we performed pairwise comparisons between control eggs (nestmate queen-laid eggs) and treatment eggs (worker-laid eggs or foreign queen-laid eggs) within groups of recipient workers originating from each social structure (monogyne or polygyne). We used one-way ANOVAs in which the significance level was Bonferroni-adjusted to $\alpha=0.025$.

We compared the survival rate of haploid eggs laid by workers and by nestmate queens using non-parametric Wilcoxon Rank Sum tests. Variables were normalized by arcsine transformations (Sokal and Rohlf 1995). All statistical analyses were conducted using the computer program JMP 7.0 (2007, SAS Institute, http://www.jmp.com).

\section{Results}

Workers from both monogyne and polygyne colonies discriminated against worker-laid eggs (Figs. 1 and 2, Table 1a). Indeed, in both types of colonies worker-laid eggs were collected by workers at a slower rate and had a lower survival rate than queen-laid eggs (pairwise comparisons; monogyne workers: collection rate: $F_{1,15}=55.27$, $P<0.0001$, and survival rate: $F_{1,29.81}=7.21, P=0.012$; polygyne workers: collection rate: $F_{1,17}=16.78, P=0.0001$, and survival rate: $\left.F_{1,21.38}=22.02, P<0.0001\right)$. Monogyne workers collected both worker-laid and queen-laid eggs at a faster rate than polygyne workers, whereas the egg survival rate did not differ significantly between the two types of workers (Table 1a). There was no significant interaction between the maternal origin of eggs (worker or queen) and the social origin of the recipient workers (monogyne or polygyne colonies; Table 1a). This suggests that workers originating from monogyne and polygyne colonies discrim- 
Table 1 Effects of the social origin of workers on the discrimination between eggs laid by nestmate workers and nestmate queens, as well as between eggs laid by nestmate queens and foreign queens originating from a colony of the same social structure as the workers

Significant results are in bold
Egg collection rate

Egg survival rate

\begin{tabular}{|c|c|c|c|c|}
\hline \multicolumn{5}{|c|}{ Worker-laid vs. queen-laid eggs } \\
\hline Origin of eggs & $F(1,32)=53.73$ & $P<0.0001$ & $F(1,51.81)=28.02$ & $P<0.0001$ \\
\hline Social origin of workers & $F(1,32)=16.42$ & $P=0.0003$ & $F(1,42.14)=2.53$ & $P=0.119$ \\
\hline Interaction & $F(1,32)=0.68$ & $P=0.416$ & $F(1,51.81)=2.73$ & $P=0.105$ \\
\hline \multicolumn{5}{|c|}{ Nestmate vs. foreign queen-laid eggs } \\
\hline Origin of eggs & $F(1,19)=1.64$ & $P=0.215$ & $F(1,40.35)=2.38$ & $P=0.131$ \\
\hline Social origin of workers & $F(1,19)=4.12$ & $P=0.057$ & $F(1,40.92)=6.22$ & $P=0.017$ \\
\hline Interaction & $F(1,19)=7.29$ & $P=0.014$ & $F(1,40.35)=4.86$ & $P=\mathbf{0 . 0 3 3}$ \\
\hline
\end{tabular}

inated worker-laid from queen-laid eggs in similar ways (Figs. 1 and 2).

The differential treatment of worker-laid and queen-laid eggs could not be explained by a discrimination against eggs laid under laboratory conditions or a discrimination against haploid eggs. The rate at which eggs from foreign queens were collected and survived did not differ significantly between eggs produced in laboratory colonies (mean $\pm \mathrm{SE}=$ $0.54 \pm 0.10$ and $0.82 \pm 0.04$, respectively; $n=9$ colonies) and eggs sampled in field colonies (Figs. 1 and 2; one-way ANOVAs, collection rate: $F_{1,9.19}=0.926, P=0.361$; Survival rate: $\left.F_{1,11.26}=0.29, P=0.602\right)$. The workers also distinguished between haploid eggs laid by nestmate queens or nestmate workers. Indeed, the survival of haploid queen-laid eggs originating from male-specialized field colonies (monogyne workers: $0.86 \pm 0.06, n=6$; polygyne workers: $0.79 \pm 0.04, n=3)$ was significantly higher than the one of haploid worker-laid eggs (Fig. 2; monogyne workers: $W=71.5, P=0.015$; polygyne workers: $W=37, P=0.043$ )

Only workers from monogyne colonies discriminated against foreign queen-laid eggs, which resulted in a significant interaction between the origin of eggs (nestmate or foreign queen) and the social origin of workers (monogyne or polygyne colonies; Table 1b). In groups of monogyne workers, eggs laid by nestmate queens were collected at a faster rate and survived better than eggs laid by foreign queens (Figs. 1 and 2; pairwise comparisons, collection rate: $F_{1,10}=5.44, P=0.042$; survival rate: $F_{1,20.02}=6.10, P=$ $0.021)$. In contrast, in groups of polygyne workers, eggs laid by nestmate and foreign queens were collected and survived at similar rates (collection rate: $F_{1,9}=2.34, P=$ 0.161 ; Survival rate: $F_{1,15.71}=0.46, P=0.508$ ).

\section{Discussion}

Our egg-acceptance bioassays show that $F$. selysi workers from monogyne and polygyne colonies discriminated eggs laid by nestmate workers from eggs laid by nestmate queens, even when only haploid eggs were compared. The lower collection rate and survival of worker-laid eggs suggest that workers police worker-laid eggs in both types of colonies. These signs of worker policing in monogyne colonies do not support the hypothesis that policing is only due to relatedness asymmetry, as workers in monogyne colonies are more related to workers' sons than to queens' sons, and should thus allow worker reproduction if it has no other cost.

The discrimination against worker-laid eggs is consistent with the hypothesis that worker policing evolved because worker reproduction decreases colony efficiency and productivity (Ratnieks 1988; Hammond and Keller 2004; Wenseleers and Ratnieks 2006). Theoretically, fairly small colony-level costs due to worker reproduction may suffice to compensate for the relatedness asymmetry and select for worker policing, even in colonies with one singly mated queen (Ratnieks 1988). However, these costs are difficult to estimate empirically, as colony fitness depends upon the cumulative effect of many variables, such as the amount of brood produced, colony size, or foraging success (Cole 1986; Gobin et al. 2003; Dijkstra and Boomsma 2007). One of the best demonstrations that worker policing limits the colony-level costs of worker reproduction came from the ant Platythyrea punctata (Hartmann et al. 2003). Because these ants are clonal, there is no relatedness asymmetry. The aggression of workers against additional reproducing workers helps to maintain a low number of reproducing individuals and contributes to increase colony efficiency by limiting the number of brood (Hartmann et al. 2003).

The discrimination between worker-laid and queen laid eggs is unlikely to be due to a selective elimination of haploid eggs, a lower intrinsic viability of worker-laid eggs, or a selective removal of eggs laid under laboratory conditions. Workers might be able to distinguish between haploid and diploid eggs, and may selectively eliminate haploid brood (Rosset and Chapuisat 2006). However, in our experiments, workers distinguished haploid worker-laid eggs from haploid queen-laid eggs, which indicate that the discrimination against worker-laid eggs can occur independently from a potential ability to distinguish haploid from diploid eggs. With respect to egg viability, the eggs remained in recipient colonies for only $24 \mathrm{~h}$. Moreover, 
worker-laid eggs and queen-laid eggs kept in similar queenless groups readily developed into adult males (Joël Meunier, unpublished results; Meunier and Chapuisat 2009). A study in A. mellifera also suggests that workers do not use egg viability to recognize worker-laid eggs, as workers did not discriminate between viable and $\mathrm{CO}_{2}$-killed queen-laid eggs, whereas they did selectively eliminate worker-laid eggs (Beekman and Oldroyd 2005). Lastly, a rejection of eggs because of laboratory conditions is unlikely, as we found that the collection and survival rates of eggs laid by queens in laboratory colonies did not differ significantly from the ones of eggs laid by queens in field colonies.

Somewhat surprisingly, the collection rate of nestmate eggs was higher in groups of monogyne workers than in groups of polygyne workers. Monogyne workers might be quicker than polygyne ones because they have a larger body size (Schwander et al. 2005). Alternatively, monogyne eggs might be easier to handle because of their smaller volume (Meunier and Chapuisat 2009).

In contrast to worker-laid eggs, eggs laid by foreign queens were only discriminated against by workers from monogyne colonies, but not by workers from polygyne colonies. The ability of monogyne workers to distinguish eggs laid by foreign monogyne queens from eggs laid by nestmate queens shows that nestmate discrimination of queen-laid eggs occurs in F. selysi. A discrimination against foreign eggs has been recently documented in another ant species of the same genus (Helanterä and Sundström 2007a). The fact that workers have some ability to discriminate against eggs laid by foreign queens might contribute to maintain the genetic integrity of monogyne colonies. It also challenges the conventional view that there is no nestmate recognition of queen-laid eggs in Hymenoptera and that queen-laid eggs are universally accepted because they are marked by a conserved queen-produced pheromone (e.g., Ratnieks and Visscher 1989; Ratnieks and Boomsma 1995; Martin et al. 2002; Pirk et al. 2003; Endler et al. 2004).

To our knowledge, our study is the first demonstration that variation in the number of queens per colony influences the ability of workers to discriminate against foreign eggs in social Hymenoptera. The discrimination against foreign eggs in one type of social structure and not the other indicates that egg recognition is affected by colony kin structure. It is likely that variation in the number of queens per colony affects the diversity and the use of cues involved in the discrimination of eggs.

The absence of discrimination against foreign queen-laid eggs in polygyne colonies might be due to larger costs of nestmate discrimination in polygyne colonies, as compared to monogyne ones. The presence of multiple queens broadens the template of cues used by workers for nestmate recognition and consequently increases the risk of costly discrimination errors (Bourke and Franks 1995; Vander Meer and Morel
1998; Helanterä and Ratnieks 2009). In addition, workers' ability to discriminate between eggs from different matrilines might lead to nepotistic behaviors within polygyne colonies, which would probably decrease the colony productivity and thus inclusive fitness of all colony members (Keller 1997; Holzer et al. 2006; Ratnieks et al. 2006).

Our data do not allow determining whether the absence of nestmate discrimination in polygyne colonies results from a lack of discrimination ability in polygyne workers or a lack of colony-specific cues on eggs laid by polygyne queens. In order to distinguish between these hypotheses, it would be of interest to investigate the chemical cues on eggs and to perform further experiments on the ability of monogyne and polygyne workers to discriminate against foreign queen-laid eggs originating from the alternative social structure.

The effect of social structure variation on nestmate discrimination seems to be context-dependent in our study population. Indeed, workers from monogyne and polygyne colonies discriminated against foreign workers and foreign queens, whatever their social structure of origin (Rosset et al. 2006; Joël Meunier, Anabelle Reber, and Michel Chapuisat, unpublished results). Moreover, workers from both types of colonies discriminated against worker-laid eggs. This suggests that the recognition of nestmate queenlaid eggs, nestmate adults and worker-laid eggs are partially independent in F. selysi. Interestingly, workers also used distinct processes to discriminate foreign from nestmate queen-laid eggs and worker-laid from queen-laid eggs in the ant $F$. fusca (Helanterä and Ratnieks 2009).

In conclusion, our results show that $F$. selysi workers have a well-developed and context-dependent ability to discriminate between eggs from various origins. The selective elimination of worker-laid eggs occurs in monogyne and polygyne colonies, which is consistent with the hypothesis that workers police each others' eggs to avoid the colonylevel productivity costs of worker reproduction. In contrast, only monogyne workers discriminated eggs laid by foreign monogyne queens from eggs laid by nestmate queens, whereas polygyne workers did not make this distinction. Workers in polygyne colonies are probably exposed to a larger diversity of cues, and their discrimination ability might be restricted in order to prevent the emergence of nepotistic conflicts among matrilines. This conditional influence of social structure variation on egg discrimination by workers is a novel example of the intricate processes modulating recognition in a social context.

Acknowledgments We thank Jessica Purcell, Michiel B. Dijkstra, Christophe Eizaguirre, Serge Aron, Lotta Sundström, and one anonymous referee for constructive comments on previous versions of this manuscript. This study was supported by grants 31003A-108263 and 31003A-125306 from the Swiss National Science Foundation. The authors declare that they have no conflict of interest. This research was done in compliance with current Swiss laws and regulations. 


\section{References}

Beekman M, Oldroyd BP (2005) Honeybee workers use cues other than egg viability for policing. Biol Lett 1:129-132

Beekman M, Oldroyd BP (2008) When workers disunite: intraspecific parasitism by eusocial bees. Annu Rev Entomol 53:19-37

Bourke AFG, Franks NR (1995) Social evolution in ants. Princeton University Press, Princeton

Breed MD, Bennett B (1987) Kin recognition in highly eusocial insects. In: Fletcher DJC, Michener CD (eds) Kin recognition in animals. John Wiley, pp. 243-285

Chapuisat M, Bocherens S, Rosset H (2004) Variable queen number in ant colonies: no impact on queen turnover, inbreeding, and population genetic differentiation in the ant Formica selysi. Evolution 58:1064-1072

Cole BJ (1986) The social-behavior of Leptothorax allardycei (Hymenoptera, Formicidae) - time budgets and the evolution of worker reproduction. Behav Ecol Sociobiol 18:165-173

Crozier RH, Pamilo P (1996) Evolution of social insect colonies: sex allocation and kin selection. Oxford University Press, Oxford

Dijkstra MB, Boomsma JJ (2007) The economy of worker reproduction in Acromyrmex leafcutter ants. Anim Behav 74:519-529

Endler A, Liebig J, Schmitt T, Parker JE, Jones GR, Schreier P, Holldobler B (2004) Surface hydrocarbons of queen eggs regulate worker reproduction in a social insect. Proc Natl Acad Sci USA 101:2945-2950

Foster KR, Ratnieks FLW (2001) Paternity, reproduction and conflict in vespine wasps: a model system for testing kin selection predictions. Behav Ecol Sociobiol 50:1-8

Foster KR, Gulliver J, Ratnieks FLW (2002) Worker policing in the European hornet Vespa crabro. Ins Soc 49:41-44

Frank SA (1995) Mutual policing and repression of competition in the evolution of cooperative groups. Nature 377:520-522

Gobin B, Heinze H, Stratz M, Roces F (2003) The energetic cost of reproductive conflicts in the ant Pachycondyla obscuricornis. J Ins Physio 49:747-752

Hamilton WD (1964) The genetical evolution of social behaviour. J Theor Biol 7:1-52

Hammond RL, Keller L (2004) Conflict over male parentage in social insects. PLoS Biol 2:1472-1482

Hardin G (1968) The tragedy of the commons. Science 162:1243-1248

Hartmann A, Wantia J, Torres JA, Heinze J (2003) Worker policing without genetic conflicts in a clonal ant. Proc Natl Acad Sci USA 100:12836-12840

Helanterä H, Ratnieks FLW (2009) Two independent mechanisms of egg recognition in worker Formica fusca ants. Behav Ecol Sociobiol 63:573-580

Helanterä H, Sundström L (2007a) Worker policing and nest mate recognition in the ant Formica fusca. Behav Ecol Sociobiol 61:1143-1149

Helanterä H, Sundström L (2007b) Worker reproduction in Formica ants. Am Nat 170:E14-E25

Hölldobler B, Wilson EO (1977) The number of queens: an important trait in ant evolution. Naturwiss 64:8-15

Holzer B, Kümmerli R, Keller L, Chapuisat M (2006) Sham nepotism as a result of intrinsic differences in brood viability in ants. Proc R Soc B-Biol Sci 273:2049-2052

Holzer B, Chapuisat M, Keller L (2008a) Foreign ant queens are accepted but produce fewer offspring. Oecologia 157:717723

Holzer B, Meunier J, Keller L, Chapuisat M (2008b) Stay of drift? Queen acceptance in the ant Formica paralugubris. Ins Soc 55:392-396
Iwanishi S, Hasegawa E, Ohkawara K (2003) Worker oviposition and policing behaviour in the myrmicine ant Aphaenogaster smythiesi japonica Forel. Anim Behav 66:513-519

Keller L (1997) Indiscriminate altruism: unduly nice parents and siblings. Trends Ecol Evol 12:99-103

Keller L, Chapuisat M (1999) Cooperation among selfish individuals in insect societies. Bioscience 49:899-909

Kikuchi T, Tsuji K, Ohnishi H, Le Breton J (2007) Caste-biased acceptance of non-nestmates in a polygynous ponerine ant. Anim Behav 73:559-565

Kutter H (1977) Formicidae-Hymenoptera. Schweizerische Entomologische Gesellschaft, Zürich

Martin SJ, Beekman M, Wossler TC, Ratnieks FLW (2002) Parasitic Cape honeybee workers, Apis mellifera capensis, evade policing. Nature 415:163-165

Meunier J, Chapuisat M (2009) The determinants of queen size in a socially polymorphic ant. J Evol Biol 22:1906-1913

Michod RE, Roze D (2001) Cooperation and conflict in the evolution of multicellularity. Heredity $86: 1-7$

Pamilo P (1991) Evolution of colony characteristics in social insects. II. Number of reproductive individuals. Am Nat 138:412-433

Pirk CWW, Neumann P, Ratnieks FLW (2003) Cape honeybees, Apis mellifera capensis, police worker-laid eggs despite the absence of relatedness benefits. Behav Ecol 14:347-352

Ratnieks FLW (1988) Reproductive harmony via mutual policing by workers in eusocial hymenoptera. Am Nat 132:217-236

Ratnieks FLW, Boomsma JJ (1995) Facultative sex allocation by workers and the evolution of polyandry by queens in social Hymenoptera. Am Nat 145:969-993

Ratnieks FLW, Visscher PK (1989) Worker policing in the honeybee. Nature 342:796-797

Ratnieks FLW, Foster KR, Wenseleers T (2006) Conflict resolution in insect societies. Ann Rev Ent 51:581-608

Reber A, Castella G, Christe P, Chapuisat M (2008) Experimentally increased group diversity improves disease resistance in an ant species. Ecol Lett 11:682-689

Reber A, Meunier J, Chapuisat M (2010) Flexible colony-founding strategies in a socially polymorphic ant. Anim Behav 78:467-472

Rosset H, Chapuisat M (2006) Sex allocation conflict in ants: when the queen rules. Curr Biol 16:328-331

Rosset H, Chapuisat M (2007) Alternative life-histories in a socially polymorphic ant. Evol Ecol 21:577-588

Rosset H, Schwander T, Chapuisat M (2006) Nestmate recognition and levels of aggression are not altered by changes in genetic diversity in a socially polymorphic ant. Anim Behav 74:951956

Schwander T, Rosset H, Chapuisat M (2005) Division of labour and worker size polymorphism in ant colonies: the impact of social and genetic factors. Behav Ecol Sociobiol 59:215221

Sokal RR, Rohlf FJ (1995) Biometry. The principles and practice of statistics in biological research, 3rd edn. Freeman, New York

Sundström L (1997) Queen acceptance and nestmate recognition in monogyne and polygyne colonies of the ant Formica truncorum. Anim Behav 53:499-510

Szathmary E, Maynard Smith J (1995) The major evolutionary transitions. Nature 374:227-231

van Zweden JS, Furst MA, Heinze J, D'Ettorre P (2007) Specialization in policing behaviour among workers in the ant Pachycondyla inversa. Proc R Soc L Ser B 274:1421-1428

Vander Meer RK, Morel L (1998) Nestmate recognition in ants. In: Vander Meer RK, Breed M, Winston M, Espelie KE (eds) Pheromone communication in social insects. Westview, Boulder, pp 79-103 
Vander Meer RK, Breed M, Winston M, Espelie KE (1998) Pheromone communication in social insects: ants, wasps, bees, and termites. Westview Press, Boulder

Vasquez GM, Silverman J (2008) Queen acceptance and the complexity of nestmate discrimination in the Argentine ant. Behav Ecol Sociobiol 62:537-548
Wenseleers T, Ratnieks FLW (2006) Comparative analysis of worker reproduction and policing in eusocial hymenoptera supports relatedness theory. Am Nat 168:E163-E179

Wenseleers T, Helanterä H, Hart A, Ratnieks FLW (2004) Worker reproduction and policing in insect societies: an ESS analysis. J Evol Biol 17:1035-1047 